\title{
Study on water purification with warm and cold season aquatic plants
}

\author{
Jiajun Sun ${ }^{1,2,4}$, Yajie Zhang ${ }^{3}$, Guangyu $\mathrm{Ma}^{6, *}$, Junhong Xiao ${ }^{3}$, Yajing $\mathrm{Cai}^{3}$, Zhi $\mathrm{Wang}^{5}$, and \\ Hongbin $\mathrm{Cao}^{1}$ \\ ${ }^{1}$ Beijing Engineering Research Center of Process Pollution Control, Institute of Process Engineering, \\ Chinese Academy of Sciences, Beijing 100190, China \\ ${ }^{2}$ University of Chinese Academy of Sciences, Beijing 100049, China \\ ${ }^{3}$ College of Environmental Science and Engineering, Beijing Forestry University, Beijing 100083, \\ China \\ ${ }^{4}$ China Xiong'an Group Co. Ltd, Baoding071000, Hebei Province, China \\ ${ }^{5}$ China Xiong'an Group Ecological Construction Investment Co. Ltd, No.2, Rongcheng071000, Hebei \\ Province, China \\ ${ }^{6}$ Environmental Development Center of the Ministry of Ecology and Environment, Beijing 100029, \\ China
}

\begin{abstract}
As a national key protection and restoration project, ecological restoration of Baiyangdian Wetland has an important significance for environmental management. As the research area in Zaozhadian wetland, the purification effect of warm season and cold season aquatic plants was studied under different overflying water qualities. It provides a theoretical and experimental basis for the ecological environment restoration and management of wetlands. The results showed that the warm season and cold season aquatic plants all played important roles on the nitrogen and phosphorus removal and maintained the stable water environmental from the nutrient release from soil. The warm season plant-mixed Myriophyllum spicatum and Ceratophyllum demersum and the cold season plantPotamogeton crispus L. can be reasonably configurated for the wetland restoration.
\end{abstract}

\section{Introduction}

Baiyangdian Wetland is located in Xiong' an New Area, Hebei Province. As the important area of national development plan of Xiong'an New Area, improvement of ecological and environmental safety of Baiyangdian Wetland through strengthening ecological environment management and restoring ecological environment function is of great significance [1-2]. Therefore, it is decided to carry out the ecological restoration of "returning farmland to wetland" [3-4]. The release of nutrients from soil to overflying water may influence the water environment in wetland. At present, there are many researches about aquatic plants purifying water quality, but few on the function of seasonal plants [5-6]. In this study, the native aquatic plants of Baiyangdian Wetland in cold and warm seasons were used to study their water

\footnotetext{
* Corresponding author: maguangyu@edcmep.org.cn
} 
purification capacity [7-9]. The findings from this study are helpful to explain the effect of different plants on ecological restoration, and also to provide a theoretical and experimental basis for the ecological environment restoration and management of wetlands [10].

\section{Materials and methods}

\subsection{Experimental design}

The experiments were carried out from warm season to old season for the wetland water purification through phytoremediation. Plastic tanks of $82 \times 64 \times 54 \mathrm{~cm}^{3}$ were used as the experimental device. Soil of $8 \mathrm{~cm}$ thick was placed at the bottom of tanks. Myriophyllum spicatum and Ceratophyllum demersum were selected as the typical warm season plants, and Potamogeton crispus L. was as the typical cold season plant. On one side of the experimental tanks a soil platform of $64 \times 15 \times 30 \mathrm{~cm}^{3}$ was built for the growth of emergent plant Canna glauca as the background plant.

The soil used in the experiments was cultivated soil of Zaozhadian Wetland, a seriously swamping and farming wetland in the whole Baiyangdian Wetland, where crops such as wheat and corn are planted for a long period. The collected soil samples were the topsoil of $0-20 \mathrm{~cm}$ in different cultivated areas.

From warm season to cold season, the overflying water in was Fuhe River (main upstream water source of Baiyangdian Wetland), the water meeting the Class IV and Class V in Discharge Standard of Pollutants for Municipal Wastewater Treatment Plant, respectively. The temperature of warm season was $25-30^{\circ} \mathrm{C}$, and that of cold season was $8-10^{\circ} \mathrm{C}$. For each overflying three experimental groups and one control group were designed. Each experimental group was divided into four subgroups with Myriophyllum spicatum, Ceratophyllum demersum, mixed Myriophyllum spicatum and Ceratophyllum demersum, and Potamogeton crispus L.

Table 1. Nutrient concentration of overlying water in warm season.

\begin{tabular}{lllll}
\hline & $\mathrm{TN}(\mathrm{mg} / \mathrm{L})$ & $\mathrm{TP}(\mathrm{mg} / \mathrm{L})$ & $\mathrm{NH}_{4}{ }^{+}-\mathrm{N}(\mathrm{mg} / \mathrm{L})$ & $\mathrm{NO}_{3}{ }^{-} \mathrm{N}(\mathrm{mg} / \mathrm{L})$ \\
\hline Fu River raw water & 1.543 & 0.158 & 0.432 & 1.108 \\
Class IV & 2.758 & 0.203 & 1.023 & 1.721 \\
Class V & 5.233 & 0.267 & 1.512 & 3.715 \\
\hline
\end{tabular}

Table 2. Nutrient concentration of overlying water in cold season.

\begin{tabular}{lllll}
\hline & $\mathrm{TN}(\mathrm{mg} / \mathrm{L})$ & $\mathrm{TP}(\mathrm{mg} / \mathrm{L})$ & $\mathrm{NH}_{4}{ }^{+}-\mathrm{N}(\mathrm{mg} / \mathrm{L})$ & $\mathrm{NO}_{3}{ }^{-}-\mathrm{N}(\mathrm{mg} / \mathrm{L})$ \\
\hline Fu River raw water & 1.473 & 0.152 & 0.428 & 1.111 \\
Class IV & 2.688 & 0.213 & 1.015 & 1.718 \\
Class V & 5.248 & 0.257 & 1.521 & 3.712 \\
\hline
\end{tabular}

\subsection{Sampling and analysis methods}

The determination of water quality was according to the National Water Quality Monitoring Methods. $\mathrm{NH}_{4}{ }^{+} \mathrm{N}$ concentration was measured by Nasser's reagent spectrophotometry method, $\mathrm{NO}_{3}{ }^{-}-\mathrm{N}$ concentration was determined by Ultraviolet spectrophotometric method, TN concentration was measured by Alkaline potassium persulfate digestion UV spectrophotometric method, and TP concentration was determined by Ammonium molybdate spectrometric method. 


\section{Results and discussion}

\subsection{Efficiency of Water Purification with Warm Season Aquatic Plants}

\subsubsection{Nitrogen removal}

Fig. 1 shows the ammonia nitrogen removal of wetland system under three kinds of overflying water. The concentration of ammonia nitrogen in all systems decreased gradually, and in the system with aquatic plant was obviously lower than that in the control, indicating the uptake of aquatic plants. The first increase or lightly decrease of ammonia nitrogen concentration in control indicated that the plant function could not compensate the ammonia nitrogen release from soil, in a long period the aquatic plants had a significant effect on transforming ammonia nitrogen due to the plant uptake and microorganism transformation. When the overlying water was raw water, the mixed Myriophyllum spicatum and Ceratophyllum demersum showed the best ammonia nitrogen removal. The three kinds of plant combination for the overflying water with Class IV and Class V water quality showed no significant difference. The purification efficiency of the three systems were similar in $76.95 \%-83.4 \%$ after $25 \mathrm{~d}$, respectively. All summer season plants showed a good water purification effect [11].
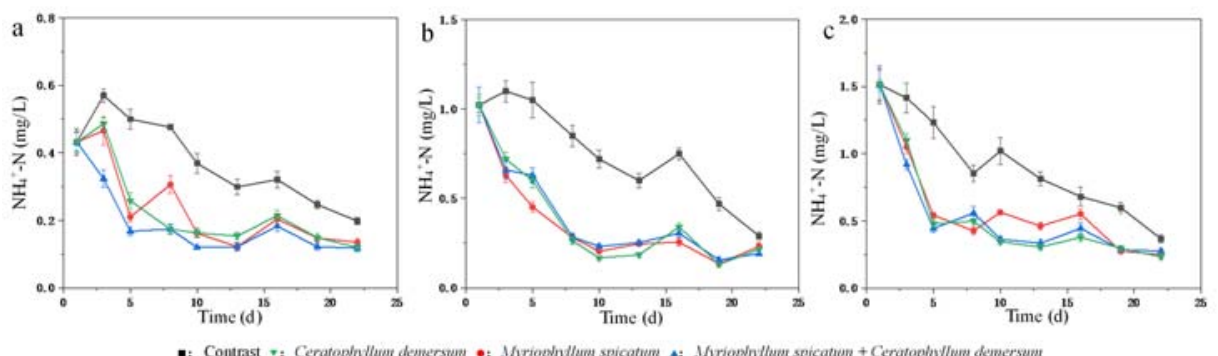

Fig. 1. Ammonia nitrogen purification effect of wetland system with the overflying water of (a) Fuhe River raw water, (b) water with Class IV, and (c) Class V.

Fig. 2 shows the nitrate nitrogen removal of wetland systems under different overflying water. At the beginning, the concentration of nitrate nitrogen quickly increased due to the possible nitrate nitrogen release from soil, then decreased gradually. After $25 \mathrm{~d}$ there was no obvious nitrate nitrogen removal, which may be caused by the continuous release of nitrate nitrogen and the ammonium nitrogen transformation. Both summer season plants and their combination removed the nitrate nitrogen and made the systems recover to the original status with the different overflying water. Ceratophyllum demersum showed the higher ability for nitrate nitrogen removal.
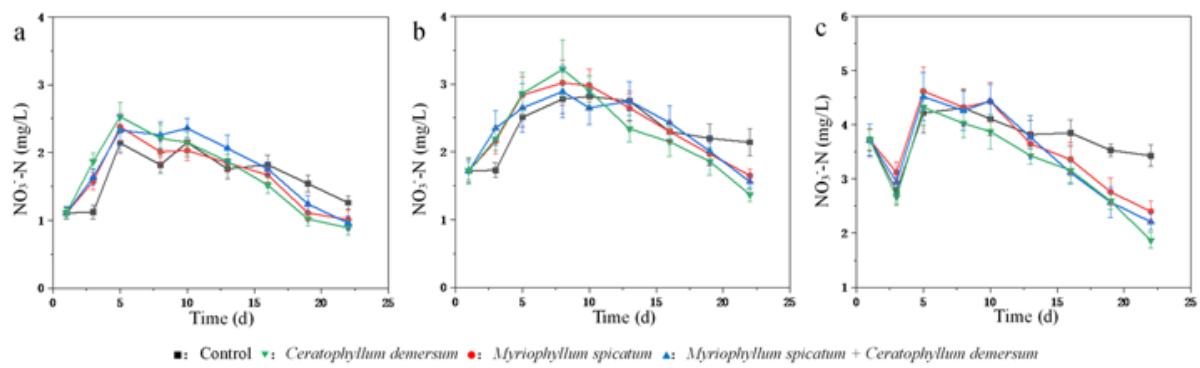

Fig. 2. Nitrate nitrogen purification effect of wetland system with the overflying water of (a) Fuhe 
River raw water, (b) the water meeting to Class IV, and (c) the water meeting to Class V.

Fig. 3 shows the TN removal of wetland systems. The TN removal showed a similar trend like nitrate nitrogen removal, which mainly included the ammonium nitrogen and nitrate nitrogen. However, the change of TN concentration was weaker than that of nitrate nitrogen because of the higher ammonium nitrogen removal. The three groups of plants had good TN purification effect for maintaining the quality of overflying water. When the quality of overflying water became worse, Myriophyllum spicatum showed a better effect, and the TN removal was between $31.27 \%$ to $38.95 \%$ [12-13].
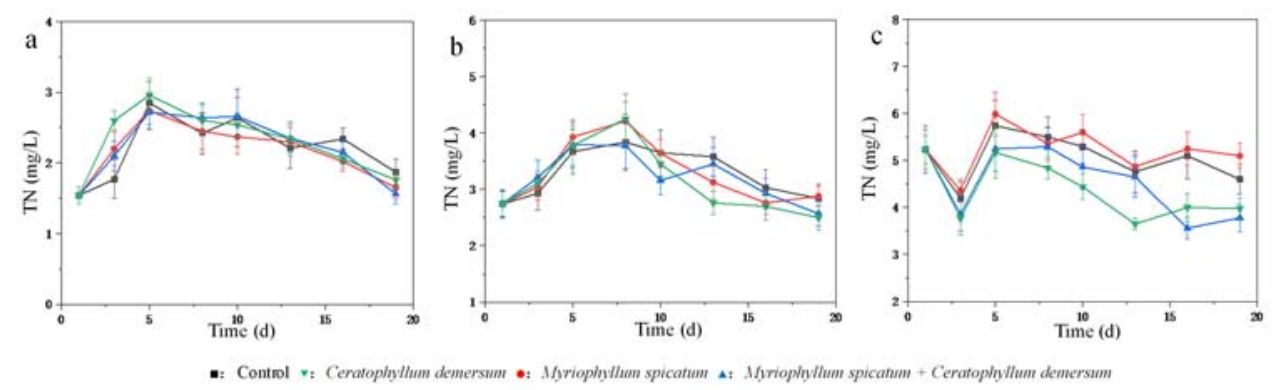

Fig. 3. TN purification effect of wetland system with the overflying water of (a) Fuhe River raw water, (b) the water meeting to Class IV, and (c) the water meeting to Class V.

\subsubsection{Phosphorus removal}

Fig. 4 shows the TP removal of different plants under three kinds of overflying water. The TP concentration with aquatic plants was lower than that in the control, indicating the uptake of the plant. The TP concentration increase in the beginning demonstrated the TP release from soil to the overflying water. Then the TP was removed from the systems due to the strong plant uptake. The three groups of plants had the high purification ability for the three kinds of overflying water. The mixed Myriophyllum spicatum and Ceratophyllum demersum showed the better ability for TP removal, and the TP removal was between $36.82 \%-42.55 \%$ [14].
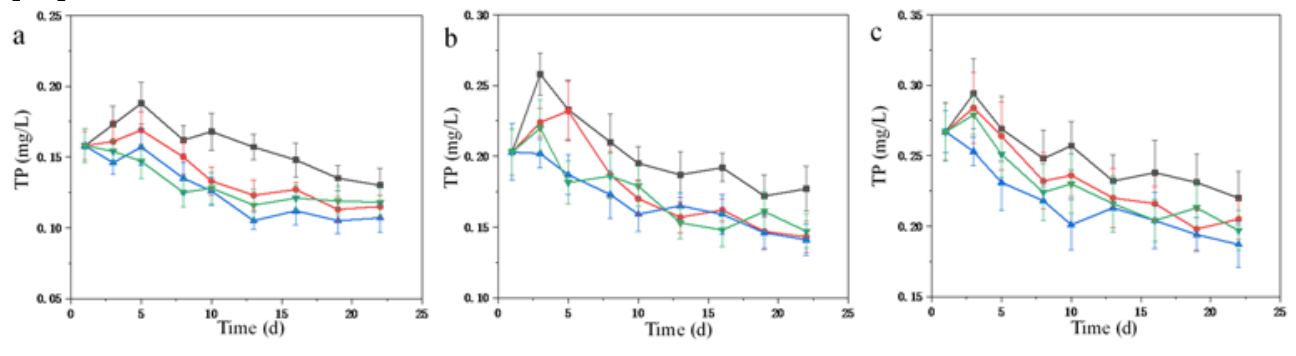

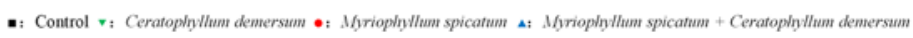

Fig. 4. TP purification effect of wetland system (The influent are (a) Raw water, (b) Class IV water and (c) Class V water).

\subsection{Efficiency of water purification with cold season aquatic plants}

Fig. 5 shows the water purification effect of Potamogeton crispus L. with three kinds of overflying water. Potamogeton crispus L. as cold season aquatic plant had nitrogen and phosphorus reduction over $50 \%$, and obviously realized the water purification in cold season. 
The average purification efficiency of TN and TP decreased with the increase of TN and TP concentration in overflying water, and the TN and TP removal was between $21.6 \%-47.2 \%$ and $32.7 \%-40.3 \%$, respectively. While the purification of ammonium nitrogen showed a high efficiency of $78.4 \%$ due to the plant uptake and microorganism transformation. Potamogeton crispus L. showed a good effect in controlling the nutrients released from soil in cold season [15].
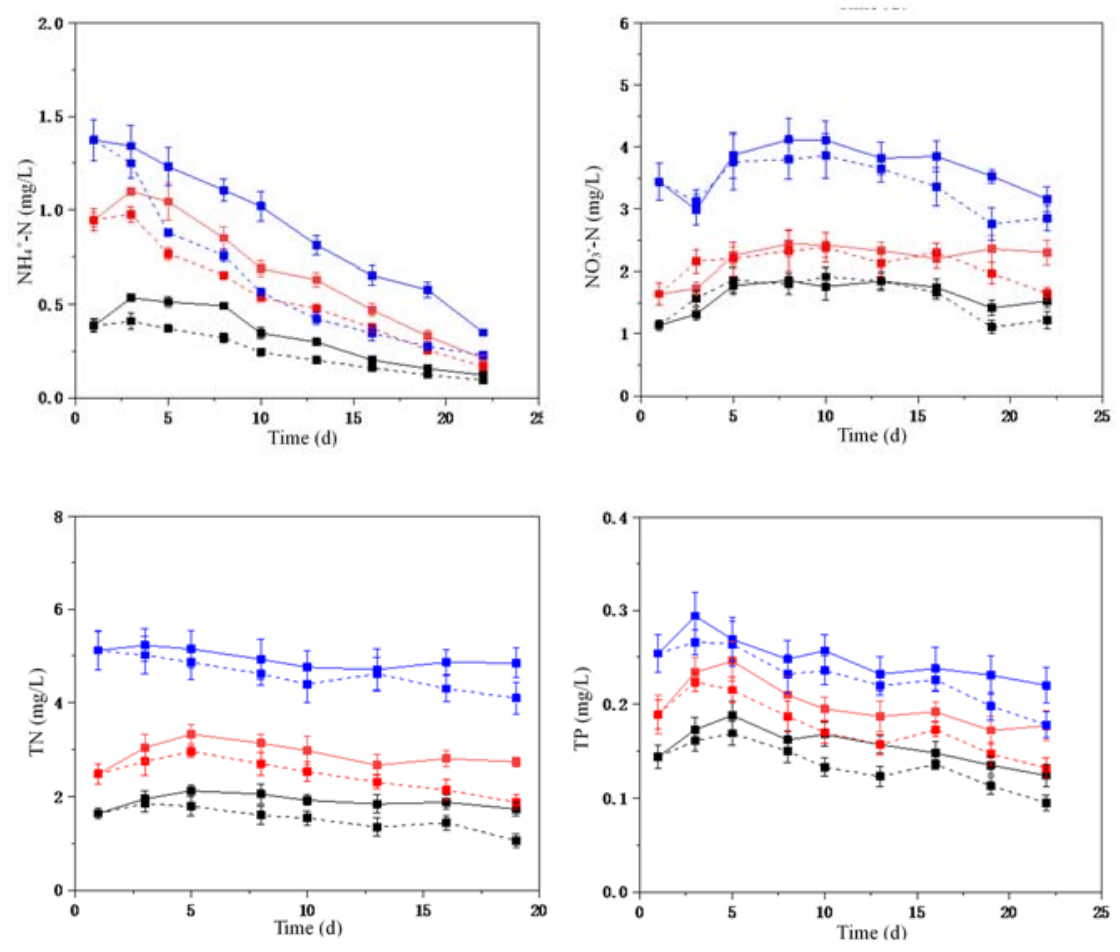

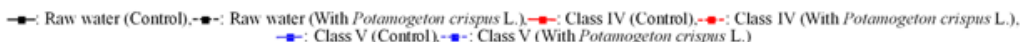

Fig. 5. TN, TP, Ammonia nitrogen and Nitrate nitrogen purification effect of different inlet waters on wetland system (The influent are Raw water, Class IV water and Class V water).

Therefore, the reasonable configuration of warm season and cold reason aquatic plants in wetland is important to keep the water environment continuously stable.

\section{Conclusions}

In this study, the function of warm season and cold season aquatic plants for water purification In Baiyangdian Wetland was investigated. In warm season, mixed plants showed better effect in water purification and keep the overflying water stable to reduce the influence of nutrient release from soil. For cold season, Potamogeton crispus L. had a good effect in water purification. In practice, the configuration of warm season and cold season aquatic plants will be important for a stable and continuous pollutant removal. 


\section{Acknowledgements}

This work is supported by the National Water Pollution Control and Treatment Science and Technology Major Project (2018ZX07110003).

\section{References}

1. Y.L. Jia, F.H. Jia, H.J. Ma, L.M. Niu, S.Q. Chen. Journal of Evironmental Management College of China. 29(03), 89-93. (2019)

2. Q. Han, R.X Tong, W.C. Sun, Y. Zhao, J.S. Yu, G.Q. Wang, Y.L. Jin. Sci Total Environ. 701, 134929. (2020)

3. Ü. Mander, M. Maddison, K. Soosaar, H. Koger, A. Teemusk, J. Truu, R. Well, M. Sebilo. Ecol. Eng. 80, 69-78. (2015)

4. B.S. Collins, R.R. Sharitz, D.P. Coughlin. Bioresour. Technol. 96(8), 937-948. (2005)

5. J. Liu, X. Zhou, C. Lu, Y.S. Wei. Wetland Science. 13(1), 7-12. (2015)

6. F. Wang, Y. Liu, T.X. Ma, X.R. Wu, H.Z. Yang. Ecol. Eng. 42(9), 124-129. (2012)

7. Y. Ge, W.J. Han, C.C. Huang, H. Wang, D. Liu, S.X. Chang, B.H. Gu, C.B. Zhang, B.J. Gu, Y.Y. Yuan, X. Fan, J. Chang. Ecol. Eng. 82, 614-623. (2015)

8. H.F. Xiong, Q. Tan, C. X. Hu. African Journal of Biotechnology. 9(35), 5722-5729. (2010)

9. Y. Li, J.F. Liu, J.Z. Liu, H. Zhang, G.X. Liao. Chinese Agricultural Science Bulletin. 31(15), 175-179. (2015)

10. X. L. Jiang, W. G. Zhang, G. Wang. Biodivers Conserv. 16, 1983-1994. (2007)

11. J. Wang, Y.F. Gu, Z.Y. Zhu, B. Wu, D.Q. Yin. Chinese Journal of Applied Ecology. 16(2), 337-340. (2005)

12. T. Cao, L.Y. Ni. Acta Hydroch Sinica. 28(3), 299-303. (2004)

13. S. Greulich, G. Bornette. Freshw Biol. 41(3), 493-506. (2010)

14. N. Nedjah, O. Hamdaoui, N. Laskri. Int. J. Eng. Res. Afr. 13, 123-129. (2015)

15. J. Xu, T. Wang, J.G. Molinos, C. Li, B. Hu, M. Pan, M. Zhang. Environ. Int. 137, 105502. (2020) 